\title{
Fog and Rain Water Collection from Trees in the Dhofar Region in the Sultanate of Oman
}

\author{
S. A. Abdul-Wahab*a, H. Al-Hinaia ${ }^{*}$ K. A. Al-Najarb, M. S. Al-Kalbanic \\ aMechanical \& Industrial Engineering Department, College of Engineering, Sultan Qaboos University, P.O. Box 33, P.C. 123, \\ Al-Khoud, Sultaname of Oman \\ ${ }^{b}$ Civil Aviation and Meteorology, Meteorology Department, Salalah Airport, Muscat, Sultanate of Oman \\ ${ }^{c}$ Civil \& Architectural Engineering Department, College of Engineering, Sultan Qaboos University, P.O. Box 33, PC 123, \\ Al-Khoud, Muscat, Sultanate of Oman
}

Received 12 May 2007; accepted 13 November 2007
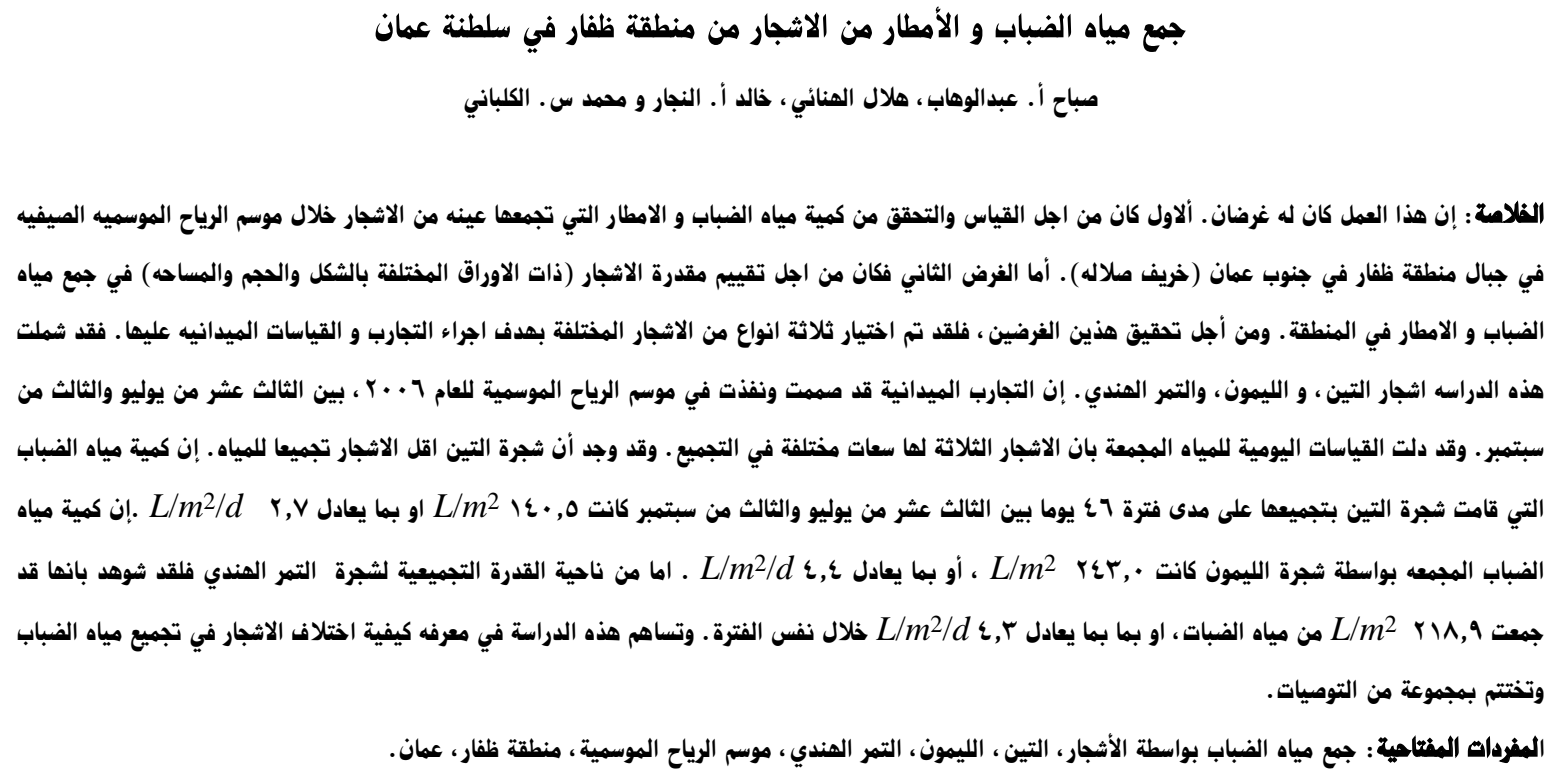

\begin{abstract}
This work had two purposes. The first was to measure and investigate the amount of fog and rain water collected by a sample of trees during the summer monsoon season in the mountains of the Dhofar region in the south of Oman. The second purpose was to assess the potential of trees with different leaf shapes, sizes and cross sectional canopy areas to collect fog and rain water in the area. In order to meet these purposes three different tree species, were selected for experimental investigation and field measurements. They included fig, lemon, and tamarind trees. The experiments were designed and implemented in the monsoon season of 2006, between the $13^{\text {th }}$ of July and the 3rd of September. The daily measurements of water collection showed that the three species of tree have different water collection capacities. It was found that the fig tree collected the least water. The fog water collection of the fig tree over a period of 47 days between the $13^{\text {th }}$ of July and the $3^{\text {rd }}$ of September was $140.5 \mathrm{~L} / \mathrm{m}^{2}$, or an average of $2.7 \mathrm{~L} / \mathrm{m}^{2} / \mathrm{d}$. The fog water collection of the lemon tree was $243.0 \mathrm{~L} / \mathrm{m}^{2}$, or an average of $4.4 \mathrm{~L} / \mathrm{m}^{2} / \mathrm{d}$. In terms of potential collection of the tamarind tree, the results showed that it collected a fog water of $218.9 \mathrm{~L} / \mathrm{m}^{2}$, or an average of $4.3 \mathrm{~L} / \mathrm{m}^{2} / \mathrm{d}$ over the same period. The study contributes to the knowledge of how different tree species collect fog and rain water, and concludes with a set of recommendations.
\end{abstract}

Keywords: Fog water collection by trees, Fig, Lemon, Tamarind monsoon season, Dhofar region, Oman

\section{Introduction}

The main water supplies in the Dhofar Region (south of the Sultanate of Oman) come from a groundwater distribution system. The exploitation of the water system contributes to the underground intrusion of salt water into the coastal plain around Salalah (Salalah is the administrative capital of Dhofar Region). Hence, as more ground

*Corresponding author's e-mail: sabah1@squ.edu.om water is extracted from the mountains, less water is available to the people living on the plain (Alesh, 1998). Moreover, the coastal plain (Salalah \& sea) is an important farming area. The groundwater is used for coconuts, bananas, vegetables and grass fodder cultivation. Recently, there has been an increase in grass fodder cultivation using large-scale groundwater irrigation (Kobayashi, 2001). In the mountain area (Jabal Dhofar), there is traditional livestock farming (mostly cows \& goats) utilizing wild vegetation as fodder. In the arid area 
(Nejid) there is traditional nomadic camel farming. These heavy demands on the water supplies stress the need to investigate all possible sources of water which may contribute to the alleviation of this situation (COWIconsult, 1992).

Non-conventional water supplies, such as fog water collection, offer possible solutions to this problem. Fog water collection has the ability to provide an alternative source of water, while at the same time reducing dependence on traditional water sources such as groundwater.

The Dhofar Region, which is located between latitudes 16 and $20^{\circ} \mathrm{N}$ occupies nearly one third of the Sultanate's total area, experiences the annual phenomenon of AlKhareef (ie. monsoon season) each summer between June and September. This region of Oman is touched by the south west monsoon and experiences by rain and thick fog caused by wet air from the Indian Ocean. Generally, fog occurs on $20 \%$ to $25 \%$ of days during the year. This fog has the potential to provide an alternative source of water. It can be collected during the monsoon season (from midJune to mid-September) and can provide substantial volumes of water for domestic use and small-scale farming in the mountains. Hence, exploitation of this phenomenon and the development of some form of fog harvesting could provide a valuable additional source of water where it is most needed. For example, the collected fog water could be used for the reforestation of the mountains, thus reducing the dependence on groundwater.

The first published studies on water collection from the monsoon clouds of the Jabal Dhofar were developed by Fallon (1978). He used wire netting to intercept water and increase the precipitation. Stanley Price, et al. (1985) started new investigations of fog water collection and the results indicated that up to $50 \mathrm{~L} / \mathrm{d}$ could be collected by a $1 \mathrm{~m}^{2}$ screen of aluminium wire mesh. A research project into fog collection technology was then undertaken in the Dhofar Region during the 1989 monsoon season by (Barros and Whitcombe, 1989). The study investigated the possible applications and benefits of fog water collection techniques. The results of the study in the coastal mountain region showed the feasibility of this technology for collecting water. It was demonstrated that in the upper elevations from 900 to $1000 \mathrm{~m}$, the average collection rates, using $1 \mathrm{~m}^{2}$ standard collectors and much larger collectors, of 30 to $40 \mathrm{~L} / \mathrm{m}^{2} / d$ were obtained over a 2 month period. This compared well with a study in Chile where 6 $\mathrm{L} / \mathrm{m}^{2} / \mathrm{d}$ was collected over a period of 12 months (Barros and Whitcombe, 1989). However, the pipe cost from collectors to the point of use was one of the major infrastructure costs that made the system uneconomic and hydraulically difficult. For the same area, a second research project was carried out during the monsoon in 1990. A number of fog-collection experiments were undertaken in this project in the coastal mountain region. The results of the experiments indicated the feasibility and applicability of the fog collection technology for collecting water. AbdulWahab, et al. (2006a) examined the potential of fog water usage in certain Jabal areas (mountains) of the Dhofar Region when fog collectors were built in the vicinity of the houses in the mountains. The aim of this work was to develop residential-type fog collectors to directly meet the needs of the mountain residents during the monsoon season, and to decrease the abstraction of groundwater. Costs were reduced by constructing the collectors close to the point of use. The collected water was used directly in the storage tanks, which were installed in the houses, to irrigate plants or to supply animals and people with water on a daily basis. A detailed examination of several other fog collection studies conducted in the Sultanate of Oman can be found elsewhere (Abdul-Wahab, et al. 2006a, 2006b; Abdul-Wahab and Lea, 2006; Alesh, 1998, 2003).

The collection of water from trees is a long established traditional practice. The experiments carried out in 1989 and 1990 in the Dhofar Region of the Sultanate of Oman clearly indicated the ability of trees to collect water in significant amounts (Barros and Whitcombe, 1989; COWIconsult, 1992). The experiments demonstrated the water collecting ability of trees in the Jabal. They also showed the potentially important role of trees in aquifer recharge in mountainous regions. This was based on the fact that much of the water collected by trees during the monsoon exceeded their immediate needs. Thus a considerable amount of water is available to seep into the soil and to percolate through into the local groundwater aquifers (Barros and Whitcombe, 1989; COWIconsult, 1992). COWIconsult (1992) reported that the trees play an important role in the recharge of groundwater. Water which percolates through the soil is usually consumed by the vegetation and so benefits the plant growth and thereby grazing on the Jabal. This means that water percolating into the groundwater aquifers is likely to benefit groundwater abstraction in either the Jabal or the Salalah plain.

When interpreting the results in terms of potential collection per tree of a given canopy size, many factors required to be considered. Among these factors are: the actual size of the canopy, its projection at right angles to the wind direction, the effect of the three dimensional canopy, the amount of collected water reaching the cistern, any evaporation during the monitoring period, the effect of the leaf size, branch and twig size, density, and the effect of the surrounding trees (COWIconsult, 1992).

The present study was designed to derive more information on collection of fog and rain water by trees during the summer monsoon season 2006 at Dhofar Region in the Sultanate of Oman. In order to meet this objective, a house in the mountains of Dhofar Region (at Ashta) was selected. At this house, fog collection experiments were carried out by using three species of tree including fig, lemon, and tamarind trees. The amount of water collected by each tree was measured in a cistern constructed under each tree. The information derived from this study will be useful in future water harvesting initiatives.

\section{Methodology}

A suitable house at Ashta in the Mountain of the Dhofar region was selected for the fog collection experiments 


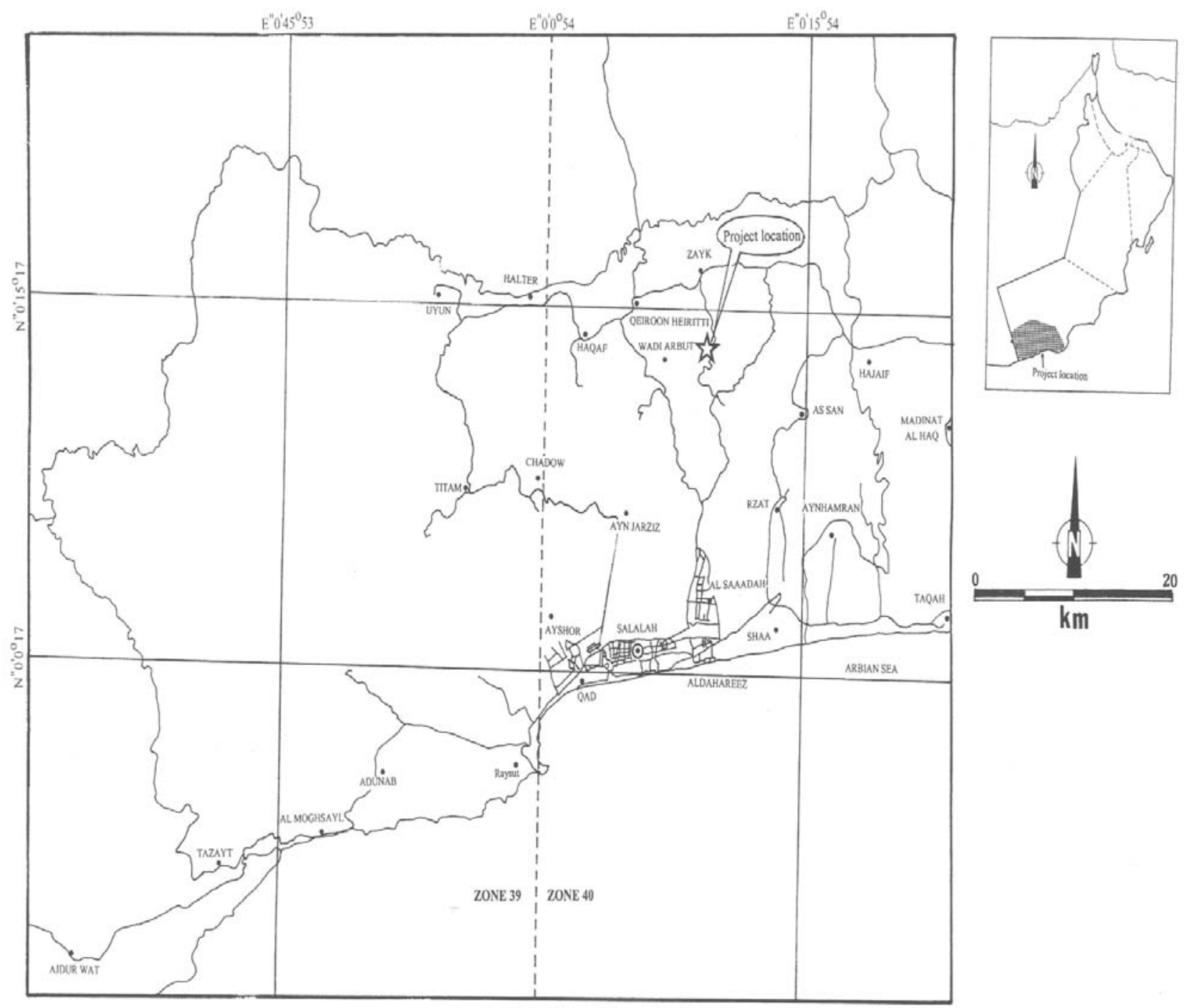

Figure 1. Map of the Sultanate of Oman and the project location at Ashta house in the mountain of Dhofar Region

(Fig. 1) by taking into account four factors, namely, (a) the potential for collecting large volumes of water, (b) the proximity of a water-poor community, (c) accessibility and (d) security.

At this house at Ashta, three specific trees were selected- a fig, a lemon and a tamarind- to harvest the fog and rain water during the monsoon season. Characteristics of the three trees used in the study together with the dimensions of their cisterns are summarized in Table 1. It can be seen from this table that the approximate cross sectional area of the tamarind tree $\left(42.76 \mathrm{~m}^{2}\right)$ was higher than that of fig $\left(16.18 \mathrm{~m}^{2}\right)$ and lemon tress $\left(20.84 \mathrm{~m}^{2}\right)$.

Under each tree a cistern was constructed to serve as collecting tank. The purpose of this cistern was to hold fog and rain water harvested by the tree during the monsoon. The cistern was constructed in such away that it was big enough for the size of the tree over it. This in fact ensured that branches of the tree did not extend beyond the rim of the tank and water thus did not drip outside the cistern. It was very important to make sure that the cistern collected all the water that the tree harvested from the fog. It should be noted that the local residents were involved to assist with the construction of the cistern underneath the three trees. The experiments at Ashta house on the three trees started on $13^{\text {th }}$ of July and lasted until $3^{\text {rd }}$ September 2006.

During the foggy conditions or rain episodes, small fog droplets were deposited on the tree and coalesced to form larger drops which flowed downwards under the force of gravity into the cistern fixed below the tree. The water was then channeled to a storage tank located in the house.

Moreover, a standard rain gauge was placed in situ at the project site to measure the daily amount of rainfall collected on the site. The purpose of this rain gauge was to determine the contribution of fog relative to the total water yield. It was assumed that whenever rain was recorded by the rain gauge, all the water deposited on the trees originated exclusively from rainfall. On the other hand, if no rain was recorded, all the water collected by the trees was assumed to originate from fog alone. Although this technique underestimates the contribution by fog, it does give some indication of the relative contributions of fog and 
Table 1. Characteristics of trees used in the study

Characteristics of the studied trees
Length of the canopy $(\mathrm{m})$
Width of the canopy (m)
Cross sectional area of the canopy $\left(\mathrm{m}^{2}\right)$
Height of tree from ground to upper branch (m)
Height of tree from ground to the low er branch (m)
Length of the leaf $(\mathrm{cm})$
Width of the leaf $(\mathrm{cm})$
Approximate area of the leaf $\left(\mathrm{cm}^{2}\right)$
Dimension of cistern beneath the tree $\left(\mathrm{cm}^{3}\right)$

$\begin{array}{ccc}\text { Fig } & \begin{array}{c}\text { Type of tree } \\ \text { Lemon }\end{array} & \text { Tamarind } \\ 4.42 & 4.88 & 6.10 \\ 3.66 & 4.27 & 7.01 \\ 16.18 & 20.84 & 42.76 \\ 6.71 & 4.08 & 5.18 \\ 1.52 & 0.82 & 1.16 \\ 5.0 & 5.7 & 3.5 \\ 3.5 & 2.7 & 1.5 \\ 17.50 & 15.39 & 5.25 \\ 310 \times 310 \times 15 & 310 \times 310 \times 15 & 400 \times 400 \times 15\end{array}$

Table 2. Total water collected and net fog water collected by the three trees during July 2006

\begin{tabular}{cccc}
\multicolumn{4}{c}{ Total fog and rainwater collected } \\
\multicolumn{4}{c}{$\left(\mathbf{L} \mathbf{m}^{\mathbf{2}} / \boldsymbol{d}\right)$} \\
Date & Fig & Lemon & Tamarind \\
13 & 12.1 & 13.1 & 0.0 \\
14 & 10.2 & 10.9 & 0.0 \\
15 & 10.5 & 4.4 & 0.0 \\
16 & 3.5 & 4.1 & 3.3 \\
17 & 1.0 & 0.7 & 0.9 \\
18 & 0.0 & 0.0 & 0.0 \\
19 & 0.0 & 0.0 & 0.0 \\
20 & 2.9 & 3.7 & 5.2 \\
21 & 8.4 & 8.7 & 5.2 \\
22 & 8.3 & 10.9 & 6.5 \\
23 & 4.7 & 10.7 & 4.4 \\
24 & 2.6 & 3.5 & 2.6 \\
25 & 0.7 & 0.7 & 1.2 \\
26 & 4.0 & 5.9 & 5.5 \\
27 & 10.4 & 22.2 & 18.4 \\
28 & 12.7 & 18.0 & 18.8 \\
29 & 9.7 & 11.2 & 14.2 \\
30 & 3.9 & 1.6 & 8.5 \\
31 & 6.5 & 6.1 & 8.4 \\
Average & $\mathbf{5 . 9}$ & $\mathbf{7 . 2}$ & $\mathbf{5 . 4}$ \\
$\left(\mathbf{L} / \mathbf{m}^{2} / \mathbf{d}\right)$ & & & \\
Total & & & $\mathbf{1 0 3 . 3}$ \\
$\left(\mathbf{L} / \mathbf{m}^{2}\right)$ & $\mathbf{1 1 2 . 0}$ & $\mathbf{1 3 6 . 5}$ & $\mathbf{1 3}$
\end{tabular}

rainfall to the total volume of water collected. Therefore, rainwater collection was subtracted from the total fog and rainwater collection to yield the fog water collection.

\section{Experimental Results}

\subsection{Fog and Rainwater Collection Data}

Tables 2, 3, and 4 illustrate the total and net fog water collected daily from the three trees during July, August and September 2006, respectively. It should be noted that the net fog water collected was determined by taking the difference between the total water collected (ie. both rain and fog water collected by tree) and rainwater.

\section{Rainwater collected $\left(L / m^{2} / d\right)$}

0.4
0.6
1.2
0.4
0.2
0.0
0.0
0.2
0.4
0.4
1.0
2.2
0.2
0.6
7.0
5.8
5.0
0.8
1.0
$\mathbf{1 . 4 4}$

$\begin{array}{ccc}\text { Fig } & \text { Lemon } & \text { Tamarind } \\ 11.7 & 12.7 & - \\ 9.6 & 10.3 & - \\ 9.3 & 3.2 & - \\ 3.1 & 3.7 & 2.9 \\ 0.8 & 0.5 & 0.7 \\ 0.0 & 0.0 & 0.0 \\ 0.0 & 0.0 & 0.0 \\ 2.7 & 3.5 & 5.0 \\ 8.0 & 8.3 & 4.8 \\ 7.9 & 10.5 & 6.1 \\ 3.7 & 9.7 & 3.4 \\ 0.4 & 1.3 & 0.4 \\ 0.5 & 0.5 & 1.0 \\ 3.4 & 5.3 & 4.9 \\ 3.4 & 15.2 & 11.4 \\ 6.9 & 12.2 & 13.0 \\ 4.7 & 6.2 & 9.2 \\ 3.1 & 0.8 & 7.7 \\ 5.5 & 5.1 & 7.4 \\ \mathbf{4 . 5} & \mathbf{5 . 7} & \mathbf{4 . 9}\end{array}$

It can be seen from these tables that the three sample trees yielded considerable difference with respect to total water collected. In general, the amount of total water collected by lemon tree was the highest, followed by tamarind tree, and finally the fig tree. The daily mean total water collected by fig, lemon, and tamarind trees during July was $5.9,7.2$, and $5.4 \mathrm{~L} / \mathrm{m}^{2} / \mathrm{d}$, respectively (Table 2 ). The monthly total fog and rainwater collected by these three trees during July was $112.0,136.5$, and $103.3 \mathrm{~L} / \mathrm{m}^{2}$, respectively.

During August, the total water collected daily by fig, lemon, and tamarind trees was 2.9, 5.3, and $5.5 \mathrm{~L} / \mathrm{m}^{2} / \mathrm{d}$, respectively (Table 3). Again, the results of water collection showed that the fig tree collected the least water of 
Table 3. Total water collected and net fog water collected by the three trees during August 2006

\begin{tabular}{|c|c|c|c|c|c|c|c|}
\hline \multirow[b]{2}{*}{ Date } & \multicolumn{3}{|c|}{$\begin{array}{l}\text { Total fog and rainwater collected } \\
\qquad\left(L / \mathrm{m}^{2} / d\right)\end{array}$} & \multirow{2}{*}{$\begin{array}{c}\text { Rainwater } \\
\text { collected } \\
\left(L / m^{2} / d\right)\end{array}$} & \multicolumn{3}{|c|}{$\begin{array}{l}\text { Net fog water collected } \\
\qquad\left(\mathrm{L} / \mathrm{m}^{2} / d\right)\end{array}$} \\
\hline & Fig & Lemon & Tamarind & & Fig & Lemon & Tamarind \\
\hline 13 & 12.1 & 13.1 & 0.0 & 0.4 & 11.7 & 12.7 & - \\
\hline 14 & 10.2 & 10.9 & 0.0 & 0.6 & 9.6 & 10.3 & - \\
\hline 15 & 10.5 & 4.4 & 0.0 & 1.2 & 9.3 & 3.2 & - \\
\hline 16 & 3.5 & 4.1 & 3.3 & 0.4 & 3.1 & 3.7 & 2.9 \\
\hline 17 & 1.0 & 0.7 & 0.9 & 0.2 & 0.8 & 0.5 & 0.7 \\
\hline 18 & 0.0 & 0.0 & 0.0 & 0.0 & 0.0 & 0.0 & 0.0 \\
\hline 19 & 0.0 & 0.0 & 0.0 & 0.0 & 0.0 & 0.0 & 0.0 \\
\hline 20 & 2.9 & 3.7 & 5.2 & 0.2 & 2.7 & 3.5 & 5.0 \\
\hline 21 & 8.4 & 8.7 & 5.2 & 0.4 & 8.0 & 8.3 & 4.8 \\
\hline 22 & 8.3 & 10.9 & 6.5 & 0.4 & 7.9 & 10.5 & 6.1 \\
\hline 23 & 4.7 & 10.7 & 4.4 & 1.0 & 3.7 & 9.7 & 3.4 \\
\hline 24 & 2.6 & 3.5 & 2.6 & 2.2 & 0.4 & 1.3 & 0.4 \\
\hline 25 & 0.7 & 0.7 & 1.2 & 0.2 & 0.5 & 0.5 & 1.0 \\
\hline 26 & 4.0 & 5.9 & 5.5 & 0.6 & 3.4 & 5.3 & 4.9 \\
\hline 27 & 10.4 & 22.2 & 18.4 & 7.0 & 3.4 & 15.2 & 11.4 \\
\hline 28 & 12.7 & 18.0 & 18.8 & 5.8 & 6.9 & 12.2 & 13.0 \\
\hline 29 & 9.7 & 11.2 & 14.2 & 5.0 & 4.7 & 6.2 & 9.2 \\
\hline 30 & 3.9 & 1.6 & 8.5 & 0.8 & 3.1 & 0.8 & 7.7 \\
\hline 31 & 6.5 & 6.1 & 8.4 & 1.0 & 5.5 & 5.1 & 7.4 \\
\hline $\begin{array}{l}\text { Average } \\
\left(L / m^{2} / d\right)\end{array}$ & 5.9 & 7.2 & 5.4 & 1.44 & 4.5 & 5.7 & 4.9 \\
\hline $\begin{array}{c}\text { Total } \\
\left(L / m^{2}\right)\end{array}$ & 112.0 & 136.5 & 103.3 & 27.4 & 84.6 & 109.1 & 78.1 \\
\hline
\end{tabular}

Table 4. Total water collected and net fog water collected by the three trees during September 2006

\begin{tabular}{|c|c|c|c|c|c|c|c|}
\hline \multirow{2}{*}{ Date } & \multicolumn{3}{|c|}{$\begin{array}{l}\text { Total fog and rainwater } \\
\text { collected }\left(L / m^{2} / d\right)\end{array}$} & \multirow{2}{*}{$\begin{array}{l}\text { Rainwater } \\
\text { collected } \\
\left(L / m^{2} / d\right)\end{array}$} & \multicolumn{3}{|c|}{$\begin{array}{l}\text { Net fog water collected } \\
\left(L / m^{2} / d\right)\end{array}$} \\
\hline & Fig & Lemon & Tamarind & & Fig & Lemon & Tamarind \\
\hline 1.0 & 2.5 & 3.3 & 5.4 & 0.4 & 2.1 & 2.9 & 5.0 \\
\hline 2.0 & 3.5 & 6.2 & 5.5 & 0.2 & 3.3 & 6.0 & 5.3 \\
\hline 3.0 & 1.0 & 1.5 & 1.1 & 0.3 & 0.7 & 1.2 & 0.8 \\
\hline $\begin{array}{l}\text { Average } \\
\left(L / m^{2} / d\right)\end{array}$ & 2.3 & 3.7 & 4.0 & 0.3 & 2.0 & 3.4 & 3.7 \\
\hline Total $\left(L / m^{2}\right)$ & 7.0 & 11.0 & 12.0 & 0.9 & 6.1 & 10.1 & 11.1 \\
\hline
\end{tabular}

the three trees. The total water collected by fig tree was 89.6 $\mathrm{L} / \mathrm{m}^{2}$, and that of the lemon tree was $163.6 \mathrm{~L} / \mathrm{m}^{2}$, and that of the tamarind tree was $169.5 \mathrm{~L} / \mathrm{m}^{2}$.

During the three days of September, the amount of fog and rainwater collected by fig was $2.3 \mathrm{~L} / \mathrm{m}^{2} / \mathrm{d}$, by lemon tree was $3.7 \mathrm{~L} / \mathrm{m}^{2} / \mathrm{d}$, and by the tamarind tree was 4.0 $\mathrm{L} / \mathrm{m}^{2} / \mathrm{d}$ (Table 4). Again, the results indicated that the fig tree collected least water of the three trees. The total water collected by the fig tree was only $7.0 \mathrm{~L} / \mathrm{m}^{2}$, while that collected by the lemon and tamarind trees was 11.0 $\mathrm{L} / \mathrm{m}^{2}$ and $12.0 \mathrm{~L} / \mathrm{m}^{2}$, respectively. It should be noted that in September the fog was not so frequent. This explains the lower amounts of water collected.

In terms of potential collection per tree, the results indicated that the fig tree collected a total of $208.6 \mathrm{~L} / \mathrm{m}^{2}$ over a period of 47 days. The lemon and tamarind trees collect- ed a total of $311.1 \mathrm{~L} / \mathrm{m}^{2}$ and $248.8 \mathrm{~L} / \mathrm{m}^{2}$, respectively, over the same period.

\subsection{Fog Collection Data}

The daily variations of fog water collected by the three trees during July and August are presented in Figs. 2a and $2 \mathrm{~b}$, respectively. It is interesting to note that the amount of fog water collected by each tree differed considerably. In general, the amount of fog water collected daily by lemon tree was the highest, followed by the tamarind and fig trees. Thus, the lemon and tamarind trees were more efficient than the fig tree in harvesting fog water. Looking at Figs. 2a and 2b, it can also be seen that the daily amount of fog water collected in July was lower than that collected in August. In certain day of August, the fog col- 
The Journal of Engineering Research Vol. 6, No.1, (2009) 51-58

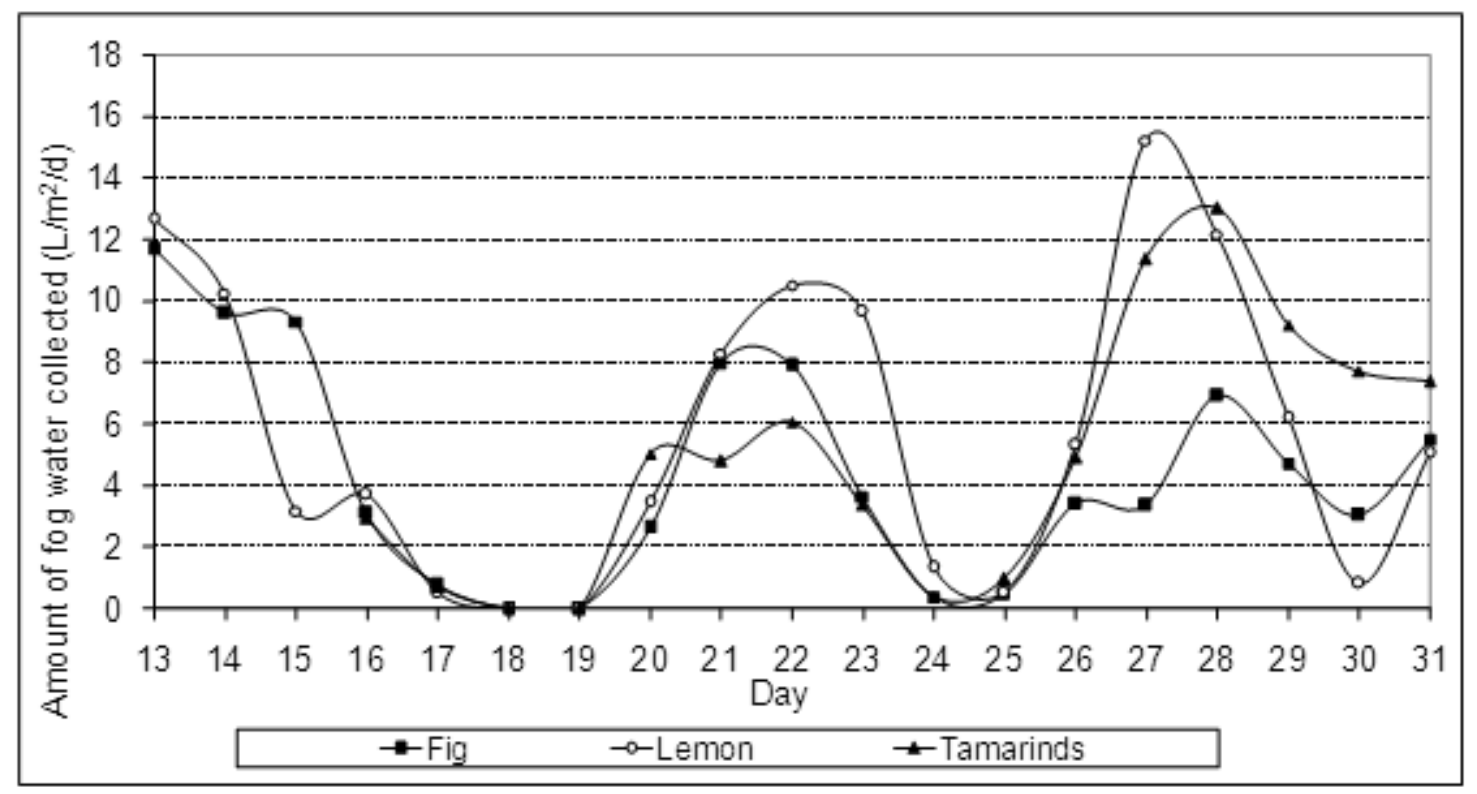

Figure 2a. Amount of fog water collected daily by the three trees during July 2006

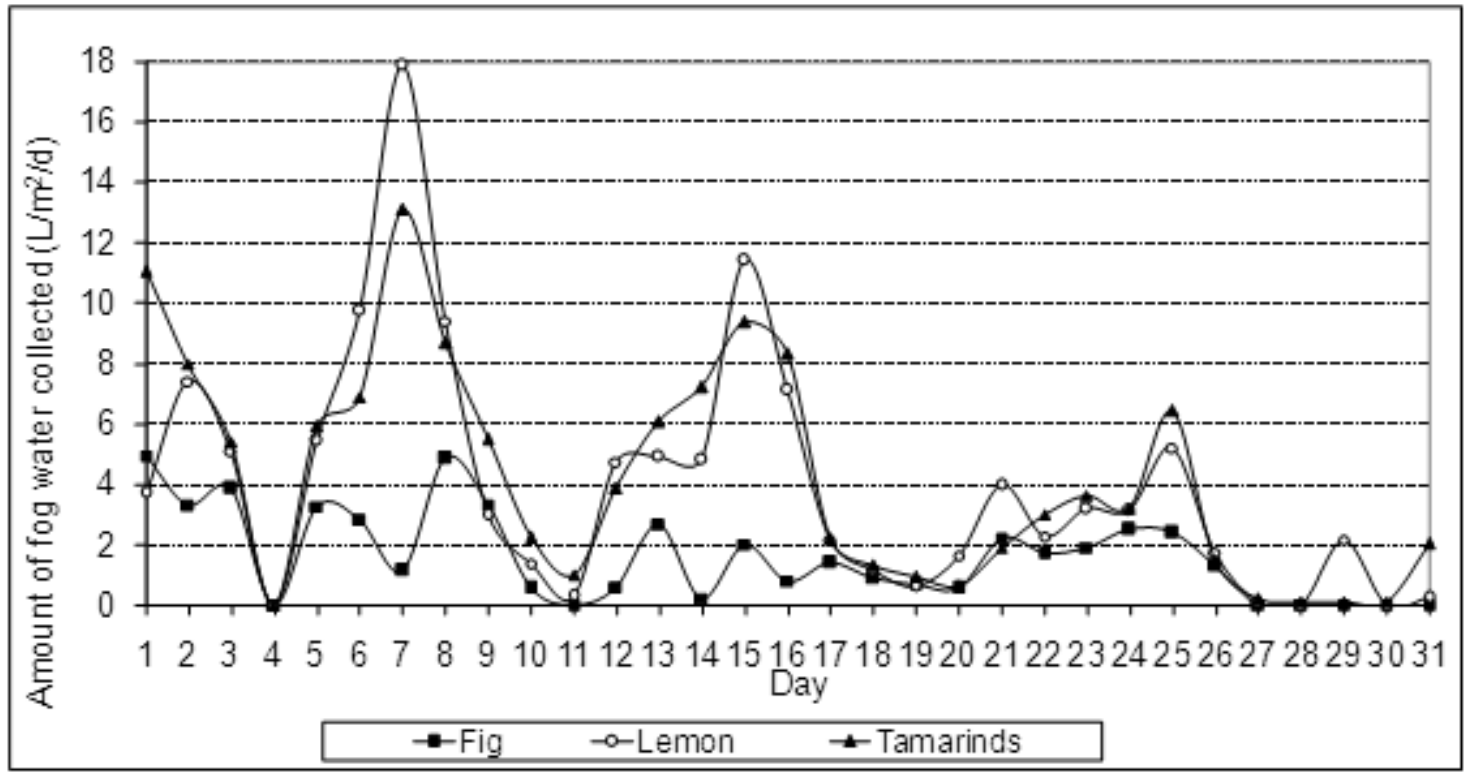

Figure 2b. Amount of fog water collected daily by the three trees during august 2006

lection by the lemon tree was as high as $19.5 \mathrm{~L} / \mathrm{m}^{2} / \mathrm{d}$ (7 August 2006).

The average fog water collected by fig, lemon, and tamarind trees during July was $4.5,5.7$, and $4.9 \mathrm{~L} / \mathrm{m}^{2} / \mathrm{d}$, respectively (Fig. 3a). The average fog collection produced by tamarind tree on August was $4.9 \mathrm{~L} / \mathrm{m}^{2} / \mathrm{d}$, whereas the fig and lemon trees produced a yield of 4.5 and 5.7 $\mathrm{L} / \mathrm{m}^{2} / \mathrm{d}$, respectively (Fig. $3 \mathrm{~b}$ ). As shown in Fig. $4 \mathrm{a}$, the total fog water collected in July by fig, lemon, and tamarind trees in the same order was 84.6, 109.1 and 78.1 $\mathrm{L} / \mathrm{m}^{2}$. The total fog collected by these trees during August in the same order was 49.8, 123.8, and $129.7 \mathrm{~L} / \mathrm{m}^{2}$ (Fig. 4b).

Over a period of 47 days in the monsoon period, the tamarind tree collected $218.9 \mathrm{~L} / \mathrm{m}^{2}$ of fog water, whereas the fig and lemon tress collected $140.5 \mathrm{~L} / \mathrm{m}^{2}$ and $243 \mathrm{~L} / \mathrm{m}^{2}$, respectively.

\section{Discussion and Conclusion}

The main aim of this study was to assess the water collection potential of trees and to investigate the fog water potential of the selected area in the mountains of the Dhofar Region in the Sultanate of Oman. The water collection efficiency of three different trees was analyzed during the period from $13^{\text {th }}$ July to $3^{\text {rd }}$ September 2006 (ie. 47 days). The experiments were conducted to study the possibilities of harvesting the water of the monsoon fog by different trees for possible use as a supplement to the water sources of the mountains of Dhofar Region. The trees included in the study were fig, lemon and tamarind trees. 
The Journal of Engineering Research Vol. 6, No.1, (2009) 51-58

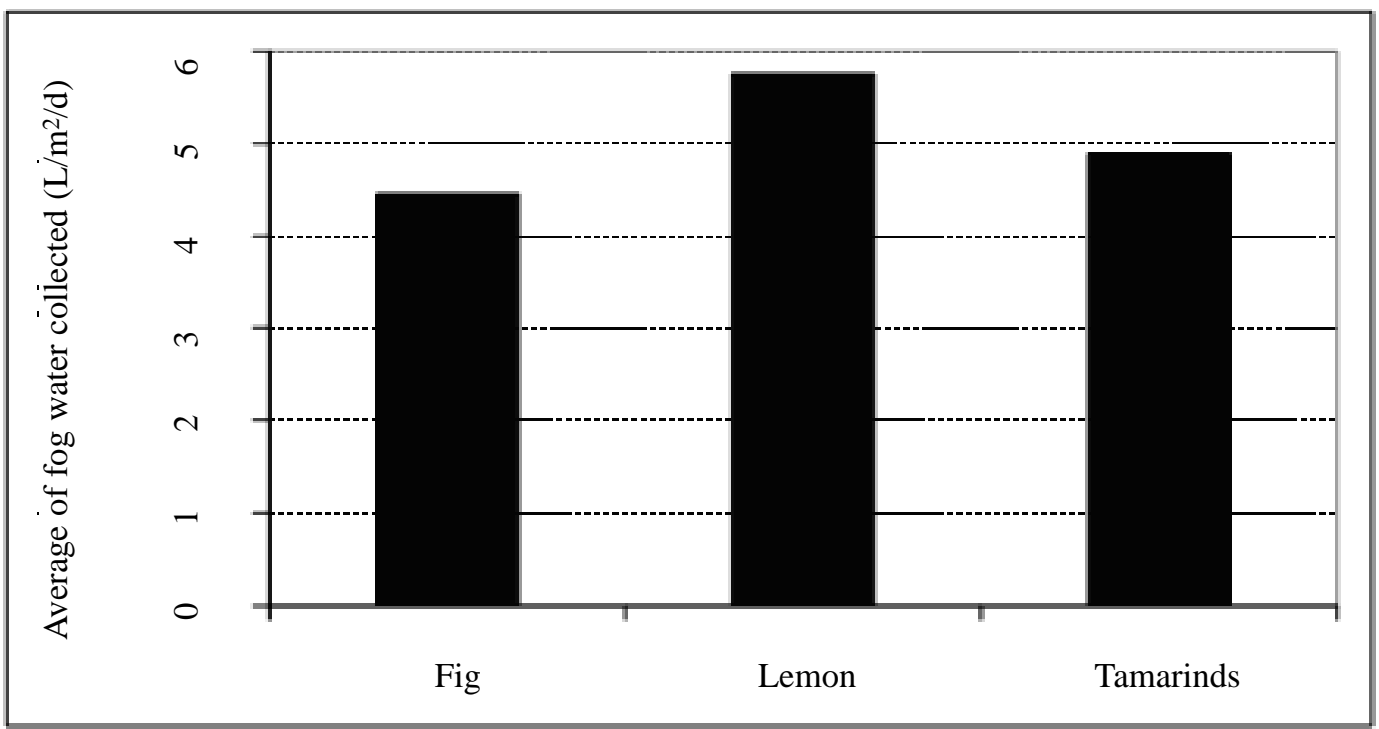

Figure 3a. Average fog water collected by the three trees during July 2006

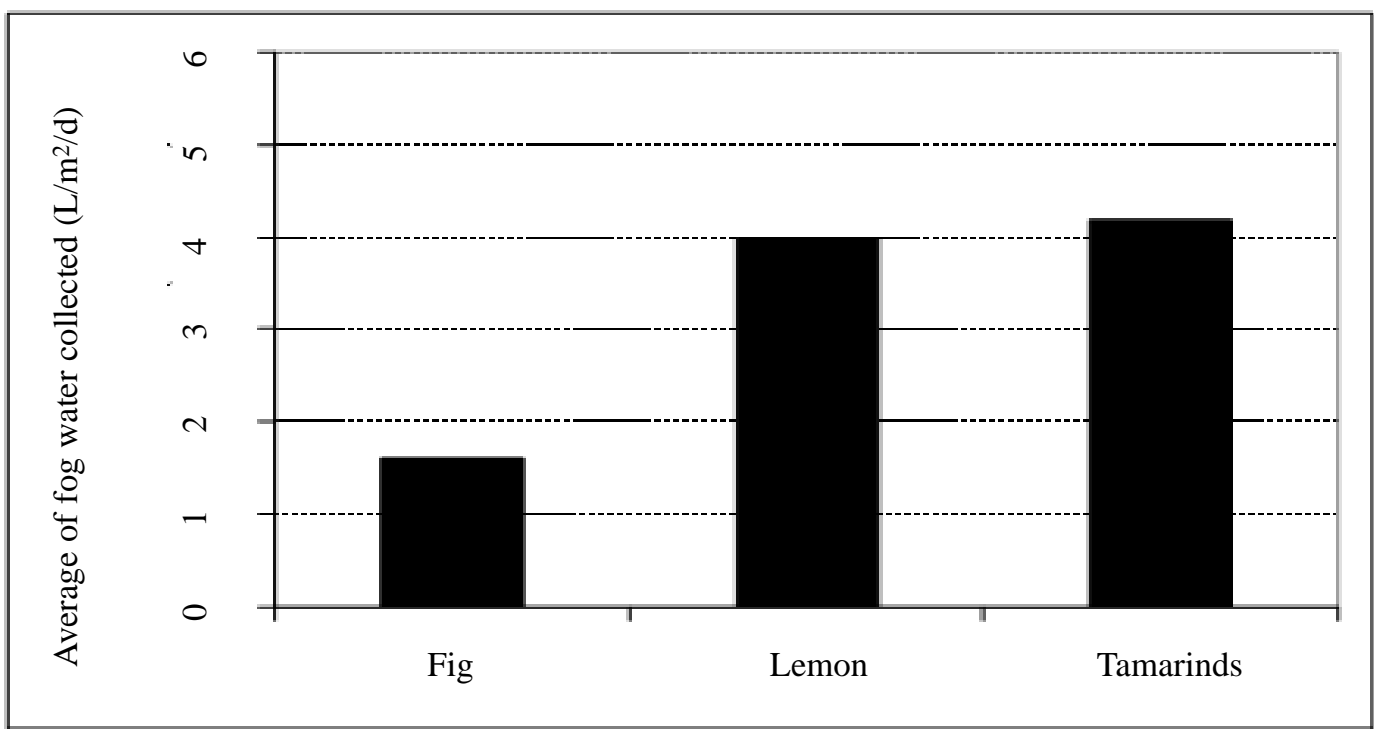

Figure 3b. Average fog water collected by the three trees during August 2006

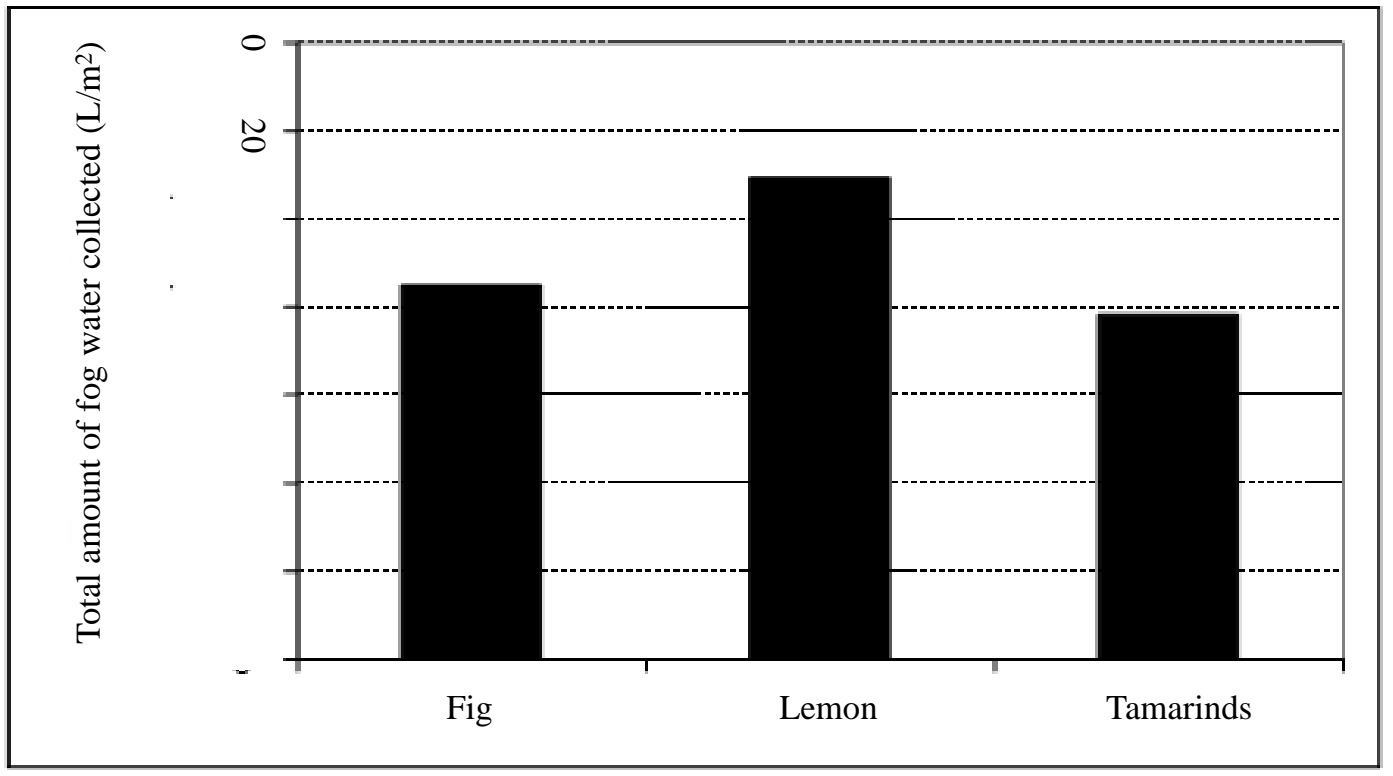


The comparisons of the water collection from the three different tress showed that large differences in collection existed as a function of the size of the leaves of the trees and the cross sectional area of their canopies. It was found that the fig tree collected the lowest amount of water. The results indicated that the total water collected during the experimental period of 47 days by the lemon tree was higher $\left(311.1 \mathrm{~L} / \mathrm{m}^{2}\right)$ than the amount of water collected by tamarind $\left(284.8 \mathrm{~L} / \mathrm{m}^{2}\right)$ and fig trees $\left(208.6 \mathrm{~L} / \mathrm{m}^{2}\right)$ over the same period.

The findings showed that the fog and rain water collected by the trees during the monsoon season provided significant amounts of water. The study also demonstrated that trees could collect amounts of water which evidently far exceed their consumption during the monsoon. The water collected can be used to supplement or replace the groundwater. The study confirmed that trees play an important role in the recharge of water to soil and groundwater.

It can be concluded from this study that trees have the potential to harvest water from fog. There is no doubt that tree planting is important for water conservation in the Dhofar region. More researches are required to identify areas where largest collection will take place and where tree planting will have the largest effect on the water resources. Therefore, more research is required to determine the optimal locations for a forestation in the Dhofar region.

\section{Acknowledgments}

The funding provided by Sultan Qaboos University (Project IG/ENG/MIED/05/02) is gratefully acknowledged.

\section{References}

Abdul-Wahab, S.A., Al-Hinai, H., Al-Najar, K.A. and AlKalbani, M.S., 2007a, "Feasibility of Fog Water Collection: A Case Study from Oman," J. of Water Supply: Research and Technology (AQUA), Vol. 56(4), pp. 275-280.
Abdul-Wahab, S.A., Al-Hinai, H., Al-Najar, K.A. and AlKalbani, M.S., 2007b, "Fog Water Harvesting: Quality of Fog Water Collected for Domestic and Agricultural Use," Environmental Engineering Science, Vol. 24(4), pp. 446-456.

Abdul-Wahab, S.A. and Lea, V., 2007, "Reviewing Fog Water Collection Eorldwide and in Oman: Between Theory and Practice," under review.

Alesh, S. A., 1998, "Work Done on Fog Collection (Moisture Capture) in the Sultanate of Oman," Proceedings of 1st Int. Conference on Fog and Fog Collection. Vancouver, pp. 417-420.

Alesh, S. A., 2003, "An Experimental Study of Fog Water Collection in Salalah Area, Sultanate of Oman," A Project/Thesis submitted in Partial Fulfillment of the requirements for the Degree of Master of Science in Hydrology, College of Science. Sultan Qaboos University, Sultanate of Oman.

Barros, J. and Whitcombe, R. P., 1989, "Fog and Rain Water Collection in Southern Region," Planning Committee for Development and Environment in the Southern Region, Sultanate of Oman.

COWIconsult, Consulting Engineering and Planners AS. 1992, "Dhofar Khareef Studies Feasibility of Fog and Rainwater Collection and Guidelines for Pilot Projects," Final Main Report. Planning Committee for Development and Environment in the Dhofar Governorate, Sultanate of Oman.

Fallon, E.F., 1978, "Mist Harvesting, Jebel Qara, Dhofar Province," Al Mawared Al Tabeieiah, Vol. 4(8), pp. 4-10.

Kobayashi, H., 2001, Role of Material Flow Analysis in Sustainable Development: Material Flow of Livestock Farming in the Dhofar Region of Oman," Technology and Development, Vol. 14, pp. 21-31.

Stanley Price, M. R., Al-Harthy, A. H. and Whitcombe, R. P., 1988, "Fog Moisture and its Ecological Effects in Oman," In Arid Lands: To-day and Tomorrow. Research and Development Conference, Tucson, Arizona, USA, October 1985: pp. 69-88. 